OPEN ACCESS

Edited by:

Yaxing Ren,

University of Warwick,

United Kingdom

Reviewed by:

Weiyu Wang,

Changsha University of Science and

Technology, China

Zhi Zhang,

Dongguan University of Technology,

China

*Correspondence:

Li L

liliarticle@163.com

Specialty section: This article was submitted to

Smart Grids,

a section of the journal Frontiers in Energy Research

Received: 01 July 2021 Accepted: 04 August 2021 Published: 04 October 2021

Citation:

Xianyong Z, Zijuan G, Yaohong $H$, Li L, Weikuan P and Jian C (2021) Power Decoupling Control of MMC and Small-Signal Stability Analysis of AC/DC Distribution Network With

Renewable Energy.

Front. Energy Res. 9:734797. doi: 10.3389/fenrg.2021.734797

\section{Power Decoupling Control of MMC and Small-Signal Stability Analysis of AC/DC Distribution Network With Renewable Energy}

\author{
Zhang Xianyong ${ }^{1,2}$, Guo Zijuan ${ }^{1}$, Huang Yaohong ${ }^{3}$, Li Li ${ }^{1 *}$, Peng Weikuan ${ }^{1}$ and Cen Jian ${ }^{1,4}$ \\ ${ }^{1}$ The College of Automation, Guangdong Polytechnic Normal University, Guangzhou, China, ${ }^{2}$ Anhui Province Key Laboratory of \\ Intelligent Building and Building Energy Saving, Anhui Jianzhu University, Hefei, China, ${ }^{3}$ Heyuan Power Supply Bureau of \\ Guangdong Power Grid Co. Ltd., Heyuan, China, ${ }^{4}$ Guangzhou Key Laboratory of Intelligent Building Equipment Information \\ Integration and Control, Guangzhou, China
}

AC/DC hybrid distribution network can realize the high penetration utilization of renewable energy and modular multilevel converter (MMC) is the key equipment to connect $\mathrm{AC}$ grid and DC grid. In this paper, the direct modulation based on the virtual resistor and the reference value of dc-bus voltage is adopted, and instantaneous-value model of threephase half-bridge MMC is derived by introducing differential-mode and common-mode component representation. Then, the decoupling control of $\mathrm{AC}$ active power and reactive power is designed based on the linear active disturbance rejection control theory (LADRC). The total disturbances including the coupling term and capacitor voltage fluctuation can be estimated by extended state observer (ESO), and then cancelled exactly. Based on the simplified average-value model of MMC, the small signal stability analysis of three-terminal AC/DC distribution network with 26-level MMCs corresponding to the TangjiawanJishan1-Jishan2 demonstration project is carried out by root locus and bode diagram method, which gives the guidance for the choice of the main circuit component and controller parameters, and shows that the virtual resistor greatly reduces the resonant peak of AC/DC distribution network. Simulation and experiment results verify the effectiveness of the power decoupling control strategy of MMC and the AC/DC distribution network can realize complex multi-directional power flow.

Keywords: MMC, power decoupling control, small signal, stability analysis, virtual resistor

\section{INTRODUCTION}

In order to realize the plan for peaking carbon dioxide emissions before 2030, it is necessary to build a new power system with renewable energy as the main body. Renewable energy such as wind and solar power is intermittent and varies greatly affected by climate conditions and geographical location. Along with the increasing proportion of renewable energy, high degree of concentration gridconnected renewable energy brings serious challenge to grid stability and power quality (Mithulananthan et al., 2013). Renewable energy access to the distribution network, to achieve local use of power generation, reduce transmission loss, become a new way to improve the utilization rate of renewable energy (Chen et al., 2016a). With the rapid development of DC renewable generation such as PV, and the popularity of DC load such as electric vehicles, DC distribution network gains great attentions because it reduces energy conversion loss and there is no inherent 
frequency stability and skin effect of ac system. Since the traditional distribution network is still ac grid, Professor Wang Peng proposed the concept of AC/DC hybrid distribution network (Wang et al., 2011). It can be compatible with the AC grid and DC gird and realize high proportion utilization of renewable energy, improve the reliability of power supply system. Therefore, AC/DC distribution network becomes the latest development trend of the current distribution network.

The converter is the crucial equipment to realize the power exchange among different distribution networks. The voltagesourced converter has become the most popular because it has the advantages of power supply to island, fast independent control of active and reactive power, and fast response of power flow reversal. With the development of the voltage level and capacity of the transmission system, the converter topology of VSC-HVDC has gradually transited from the two-level or threelevel structure to the MMC (Alassi et al., 2019). MMC has cascaded sub-modules (SMs), instead of the power electronic devices to connect in series directly, which has the advantages of low switching frequency, low switching loss, good waveform quality, and easy capacity expansion, etc. (Lesnicar and Marquardt, 2004). There is the half-bridge SM, the full-bridge SM, the clamp double SM, and three-level SM and so on (Marquardt, 2010; Marquardt, 2011). Although the full-bridge SM and the clamp double SM has the ability of DC fault selfcleaning, the half-bridge SM becomes the dominant topology because of its simple control and low cost.

The AC and DC voltages of MMC are obtained simultaneously by switching the SMs. The modulation strategy of MMC mainly includes the nearest level modulation (NLM) and the phaseshifted-carrier PWM (PSC-PWM) (Debnath et al., 2015). The NLM needs to measure the current direction and sort the capacitor voltage of SM, which needs additional control loops. PSC-PWM generates $\mathrm{N}$ group of PWM signals when $\mathrm{N}$ groups of triangular carriers with phase offsets of $2 \pi / N$ angle are compared with the same modulation wave. The PSC-PWM is much simpler and widely used in MMC. The steady state characteristic and open-loop control strategy of MMC are studied in (Antonopoulos et al., 2009; Angquist et al., 2011). The open-loop scheme analysis usually assumes that the modulation indices and the AC current are both sinusoidal, and doesn't consider capacitor voltage ripple, which doesn't reflect the real case. The closed-loop controller design of MMC is similar to that of two-level converters (Guan and $\mathrm{Xu}, 2012$ ). In order to avoid the instability, the reference value of the dc-bus voltage (Harnefors et al., 2013) or the estimated capacitor voltage (Vasiladiotis et al., 2014) is used to calculate the modulation index, which leads to the strong coupling between active and reactive power (Yang et al., 2018).

A particular average-value model of MMC is presented and the coupled transient response is revealed in (Yang et al., 2017). Reference (Wang and Wang, 2019) identifies four power coupling paths and two power influence factors. The above decoupling strategies usually adopt PI controller and execute the exact cancellation according to the analytical expressions. But the analytical expression can't describe the complex coupling among ac current, circulating current and dc current under different operation conditions precisely. Disturbance-observer- based control instead of precise modeling provides a new idea. A number of widely used linear and nonlinear disturbance estimation techniques such as DUE and DUEA are reviewed in (Chen et al., 2016b). The active disturbance rejection control (ADRC) has obtained excellent control results in motion control (Alonge et al., 2017; Liu et al., 2017; Wang et al., 2019; Liu et al., 2020). The fundamental part of ADRC is the extended state observer (ESO), which estimates the total disturbances including unknown uncertainties and external disturbances. The early MMC based HVDC project is mainly single terminal or twoterminal for wind farm integration (Friedrich, 2010; Bergna Diaz et al., 2015). With the accretion of the grid and renewable energy capacity and the improved requirement of power supply reliability, multi-terminal MMC based HVDC projects becomes the mainstreams (Rao, 2015; Trinh et al., 2016; Zhang et al., 2017). The MMC based multi-terminal HVDC is a complex power electronic system. It is a challenge to investigate the dynamic performance and stability based on appropriate modeling and simulation method to satisfy planning and operational criteria (Adam and Williams, 2014; Wang et al., 2016a; Wang et al., 2016b). Averaged model (Saad et al., 2013), detailed equivalent circuit model (Ahmed et al., 2016), and equivalent circuit model (Xiang et al., 2017) are established to simulate the electromagnetic transient response of HVDC system. When MMC can't provide sufficient damping, the multi-terminal DC grid is easy to resonance and instability. Therefore, virtual impedance damping control is proposed to improve the DC grid's performance (Li et al., 2019; Wan et al., 2018). Small signal stability analyses are used to design the system dynamics and select the controller parameters and DC inductance (Kotb et al., 2016; Li et al., 2018; Lu et al., 2018). On the one hand, above small signal model usually comprises ac current dynamics, phase-locked loop, and MMC dynamics, and DC networks, which is too complex and not easy to identify the key impact factor. On the other hand, above small signal model doesn't consider the effect of the modulation strategy and the virtual impedance simultaneously (Li et al., 2018).

MMC is the key equipment to connect the AC grid and DC grid. MMC based HVDC project usually has unidirectional power flow. But the MMC based DC/AC hybrid distribution network has complex multidirectional power flow. There is seldom theoretical and experimental research about the MMC based medium-voltage DC/AC distribution network. In this paper, the MMC based Tangjiawan-Jishan1-Jishan2 DC/AC distribution network demonstration project is studied. The contribution of this paper is summarized as followings: 1) a novel instantaneous-value model of MMC which introducing the differential-mode and common-mode component representation is derived. The direct modulation strategy is adopted based on the virtual resistor and the reference value of dc-bus voltage, which avoids the direct measurement of SM capacitor voltage and is easy to calculate. 2) AC active and reactive power decoupling control based on LADRC is realized, which doesn't require the precise modeling of coupling factor and uncertainty. 3) a simplified average-value model of $\mathrm{MMC}$ is deduced and small signal stability of AC/DC distribution network is analyzed, which identifies the damping effect of the virtual resistor. 4) 


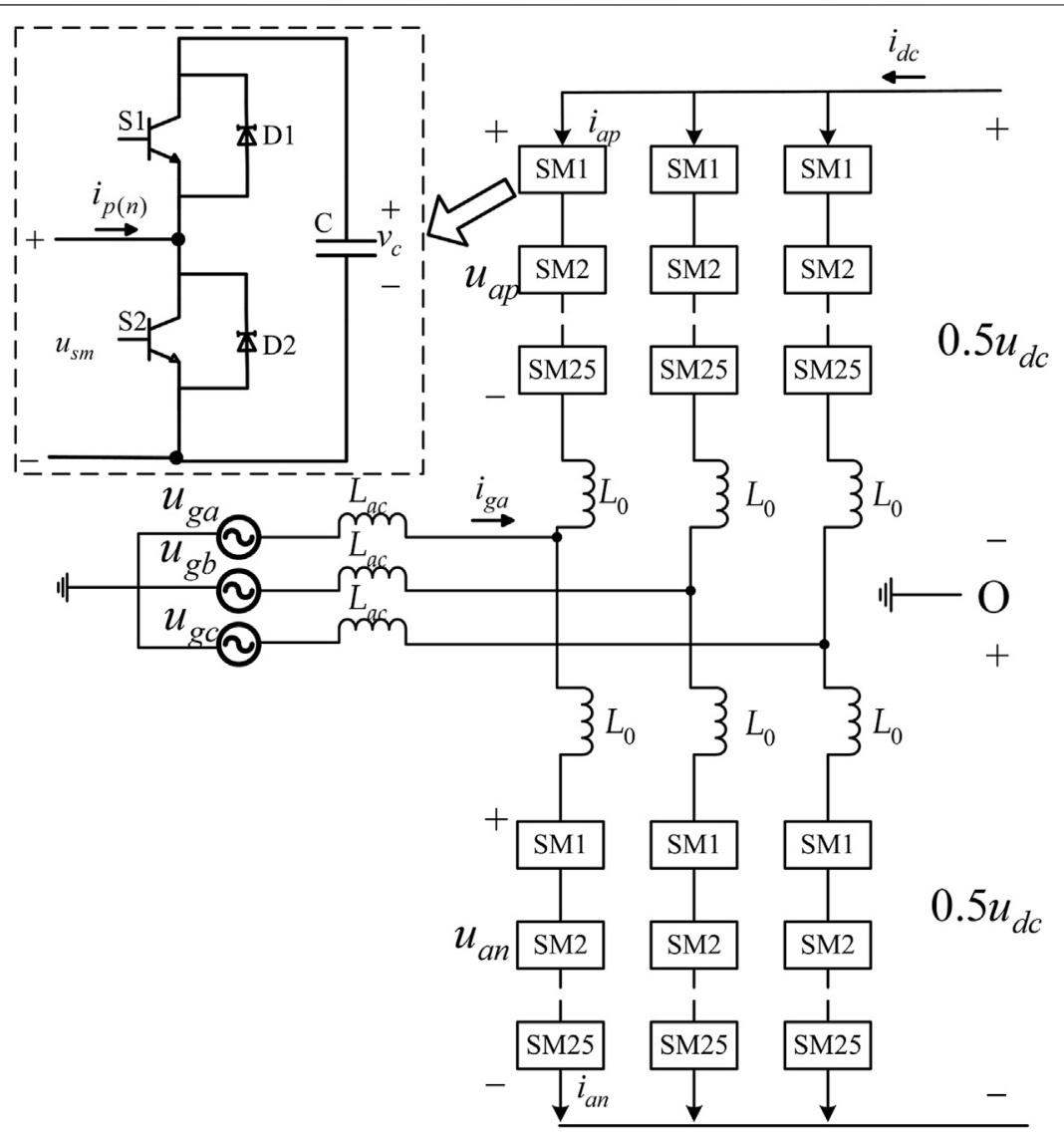

FIGURE 1 | Structure of MMC.

theoretical and empirical research on Tangjiawan-Jishan1Jishan2 DC/AC distribution network demonstration project are carried out.

The rest of this paper is organized as follows. Section 2 introduces the common-mode and differential-mode component instantaneous-value model of MMC. Section 3 presents ac power decoupling control of MMC based on LADRC. Section 4 is the small signal stability analysis of $\mathrm{MMC}$ based three-terminal AC/DC distribution network. Section 5 is the simulations based on PSCAD. Section 6 is experiments on the Tangjiawan-Jishan1Jishan2 AC/DC distribution network. Section 7 is the conclusions.

\section{INSTANTANEOUS-VALUE MODEL OF MODULAR MULTILEVEL CONVERTER}

Figure 1 shows the structure of three-phase half-brideg MMC. Each phase consists of the upper and lower arm. Each uppper (lower) arm has $\mathrm{N}$ half-bridge submodules and a inductor $L_{0}$ in series. $L_{0}$ is used to restrain the circulating current and buffer the short circuit. $p(n)$ presents the vairable of upper (lower) arms. $u_{j p}\left(u_{j n}\right)$ and $i_{j p}\left(i_{j n}\right)$ are the upper (lower) arm voltage and current of phase $j(j=a, b, c) . L_{a c}$ is the inductor connecting the ac-grid and MMC. $C$ is the submodule capacitor. $u_{g j}$ and $i_{g j}$ are the ac voltage and current respectively. $u_{d c}$ and $i_{d c}$ are the dc voltage and current respectively.

MMC is a complex AC-DC coupling system. The commonmode and differential-mode component representation is introduced to analyze the coupling system.

Defining the common-mode component of variable $x$ is

$$
\overline{\mathrm{x}_{j}}=0.5\left(x_{j p}+x_{j n}\right)
$$

The differential-mode component of variable $x$ is

$$
\widehat{x}_{j}=0.5\left(x_{j p}-x_{j n}\right)
$$

where $x_{j p}\left(x_{j n}\right)$ is the upper (lower) arm variable of phase $j$.

The arm current dynamics of phase $j$ are

$$
\begin{aligned}
& L_{0} \frac{d i_{j p}}{d t}-L_{a c} \frac{d i_{g j}}{d t}=\frac{u_{d c}}{2}-u_{j p}-u_{g j} \\
& L_{0} \frac{d i_{j n}}{d t}+L_{a c} \frac{d i_{g j}}{d t}=\frac{u_{d c}}{2}-u_{j n}+u_{g j}
\end{aligned}
$$

Let $\quad \overline{i_{j}}=0.5\left(i_{j p}+i_{j n}\right), \hat{i_{j}}=0.5\left(i_{j p}-i_{j n}\right), \quad \overline{u_{j}}=0.5\left(u_{j p}+u_{j n}\right)$, $\widehat{u}_{j}=0.5\left(u_{j p}-u_{j n}\right)$, Then Eqs 3, 4 can be expressed as 


$$
\begin{gathered}
\left(2 L_{a c}+L_{0}\right) \frac{d \widehat{i_{j}}}{d t}=-\widehat{u}_{j}-u_{g j} \\
2 L_{0} \frac{d \overline{i_{j}}}{d t}=u_{d c}-2 \overline{u_{j}}
\end{gathered}
$$

Eq. 5 shows that the differential-mode current $\hat{i_{j}}$ can be controlled by the differential-mode voltage $\widehat{u}_{\mathrm{j}}$. Eq. 6 shows that the common-mode current $\overline{i_{j}}$ can be controlled by the common-mode voltage $\overline{u_{j}}$. Therefore the independent control of $\hat{i_{j}}$ and $\overline{i_{j}}$ can be realized, which greatly simplifies the arm current controller design.

When the switch S1 is on and S2 is off, $U_{s m}$ is equal to the capacitor voltage. When the switch S2 is on and S1 is off, $U_{s m}$ is zero. Arm voltage is obtained from capacitor voltage by PSCPWM. The relationship between the arm voltage and the capacitor voltage is

$$
\begin{aligned}
\mathrm{u}_{j p} & =m_{j \mathrm{p}} v_{j p c} \\
\mathrm{u}_{j n} & =m_{j n} v_{j n c}
\end{aligned}
$$

where $v_{j p c}\left(v_{j n c}\right)$ is the sum of upper (lower) arm capacitor voltages, $m_{j p}$ and $m_{j n}$ are the modulation indices.

Let $\overline{m_{j}}=0.5\left(m_{j p}+m_{j n}\right), \widehat{m}_{j}=0.5\left(m_{j p}-m_{j n}\right), \overline{v_{j c}}=0.5\left(v_{j p c}+\right.$ $\left.v_{j n c}\right), \widehat{v_{j c}}=0.5\left(v_{j p c}-v_{j n c}\right)$, Eq. 7 can be expressed as

$$
\begin{aligned}
& \overline{u_{j}}=\overline{m_{j} v_{j c}}+\widehat{m}_{j} \widehat{v_{j c}} \\
& \widehat{u}_{j}=\overline{m_{j}} \widehat{v_{j c}}+\widehat{m}_{j} \overline{v_{j c}}
\end{aligned}
$$

Supposed that the volatge balance control of submodule capacitor is realized for each upper or lower arm, and then the dynamics of capacitor voltages are

$$
\begin{aligned}
& \frac{C}{\mathrm{~N}} \frac{d v_{j p c}}{d t}=m_{j p} i_{j p} \\
& \frac{C}{N} \frac{d v_{j n c}}{d t}=m_{j n} i_{j n}
\end{aligned}
$$

Adopting the common-mode and differential-mode component representation, Eqs 11 and 12 can be expressed as

$$
\begin{aligned}
\frac{C}{N} \frac{d \overline{v_{j c}}}{d t} & =\overline{m_{j}} \overline{i_{j}}+\widehat{m}_{j} \hat{i_{j}} \\
\frac{C}{N} \frac{d \widehat{v_{j c}}}{d t} & =\bar{m}_{j} \hat{i_{j}}+\widehat{m}_{j} \overline{i_{j}}
\end{aligned}
$$

It shows that the common-mode component and the differential-mode component of the capacitor voltage have complex nonlinear characteristics.

According to (Eqs 5, 6, 9, 10, 13, 14), the differential-mode current $\widehat{i_{j}}$ is mainly determined by $\widehat{m}_{j}$. The common-mode current $\overline{i_{j}}$ is mainly determined by $\overline{m_{j}}$. Because the capacitor voltage is hard to measure and DC grid is also easy to resonate because of lack of damping, the modulation indices are determined as followings.

$$
\begin{gathered}
\overline{m_{j}}=0.5+R_{v} \overline{i_{j}} / v_{\mathrm{eq} c}^{*} \\
\widehat{m}_{\mathrm{j}}=\widehat{u_{j}^{*}} / v_{\mathrm{eq} c}^{*}
\end{gathered}
$$

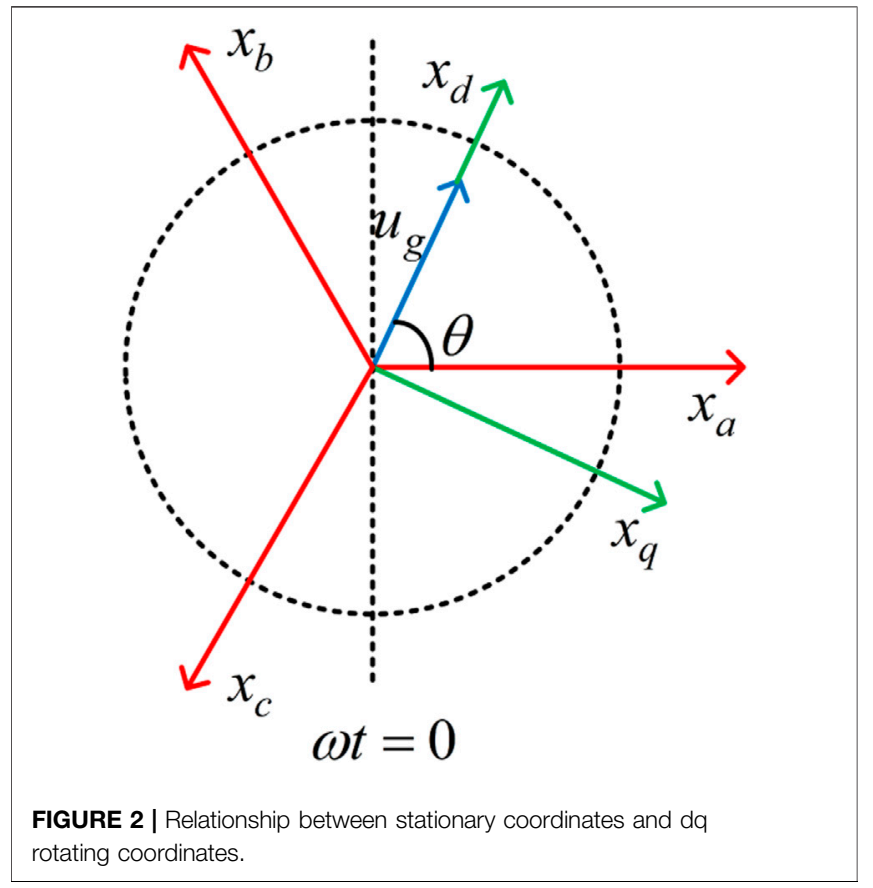

where $v_{\text {eqc }}^{*}$ is the reference value of dc-bus voltage, and it is also the reference value of the sum of the upper (lower) arm capacitor voltage. $v_{\text {eqc }}^{*}$ is used to avoid the measurement of the real capacitor voltage and the virtual resistor $R_{v}$ is added to increase the damping of DC grid. $\widehat{u_{j}^{*}}$ is the reference value of the differential-mode component of arm voltage, and it is also the control variable.

\section{AC POWER DECOUPLING CONTROL OF MODULAR MULTILEVEL CONVERTER BASED ON LINEAR ACTIVE DISTURBANCE REJECTION CONTROL THEORY}

\subsection{AC Power Modeling of Modular Multilevel Converter}

MMC can exchange active power and reactive power with acgrid. From Figure 1, ac current in the three-phase stationary coordinates is

$$
i_{g j}=i_{j n}-i_{j p}=-2 \widehat{i_{j}}
$$

Power is usually analyze in the $d q$ rotating coordinates. The relationship between the three-phase stationary coordinates and $\mathrm{dq}$ rotating coordinates is shown in Figure 2(Lu et al., 2018). We can get

$$
\left[\begin{array}{l}
x_{d} \\
x_{q} \\
x_{0}
\end{array}\right]=\frac{2}{3}\left[\begin{array}{ccc}
\cos \theta & \cos \left(\theta-\frac{2 \pi}{3}\right) & \cos \left(\theta+\frac{2 \pi}{3}\right) \\
\sin \theta & \sin \left(\theta-\frac{2 \pi}{3}\right) & \sin \left(\theta+\frac{2 \pi}{3}\right) \\
\frac{1}{2} & \frac{1}{2} & \frac{1}{2}
\end{array}\right]\left[\begin{array}{c}
x_{a} \\
x_{b} \\
x_{c}
\end{array}\right]
$$


where $\theta=\theta_{0}+\int_{0}^{\mathrm{t}} \omega d t$ is the angle between the coordinates. $x_{d}, x_{q}$, and $x_{0}$ are the variables in the $d q$ coordinates. $x_{a}, x_{b}$, and $x_{c}$ are the variables in the three-phase stationary coordinates.

When the $\mathrm{d}$-axis of the rotating coordinates is aligned with the grid voltage space vector, that is $u_{g q}=0$, the ac active power and reactive power can be calculated as

$$
\left\{\begin{array}{l}
P_{s}=1.5 u_{g d} i_{g d}=-3 u_{g d} \hat{i_{d}} \\
Q_{s}=1.5 u_{g d} i_{g q}=-3 u_{g d} \hat{i_{q}}
\end{array}\right.
$$

where active power is determined by $\hat{i_{d}}$ and reactive power is determined by $\hat{i_{q}}$. The power decoupling control is simplified to the differential-mode arm current decoupling control.

The differential-mode arm current in eq. 5 can be expressed in $\mathrm{dq}$ rotating coordinates as

$$
\left\{\begin{array}{l}
2 L_{s} \frac{d \widehat{i_{d}}}{d t}=-2 \omega L \widehat{i_{q}}-\widehat{u_{d}}-u_{g d} \\
2 L_{s} \frac{d \widehat{i_{q}}}{d t}=2 \omega L \widehat{i_{d}}-\widehat{u_{q}}-u_{g q}
\end{array}\right.
$$

Where $L_{s}=L_{0} / 2+L_{a c}$.

According to Eq. 16, we can get

$$
\left\{\begin{array}{l}
2 L_{s} \frac{d \widehat{i_{d}}}{d t}=-2 \omega L \widehat{i_{q}}-\frac{v_{e q c}}{v_{\text {eqc }}^{*}} \widehat{u_{d}^{*}}-u_{g d} \\
2 L_{s} \frac{d \widehat{i_{q}}}{d t}=2 \omega L \hat{i_{d}}-\frac{v_{e q c}}{v_{\text {eqc }}^{*}} \widehat{u_{q}^{*}}-u_{g q}
\end{array}\right.
$$

where $v_{e q c}$ is the actual value of the sum of the upper (lower) arm capacitor voltages. Eqs 13 and 14 show that $v_{e q c}$ is nonlinear and hard to measure, so it is difficult to determine the control variables $\widehat{u_{d}^{*}}$ and $\widehat{v_{\mathrm{q}}^{*}}$.

\subsection{AC Power Decoupling Controller Design Based on Linear Active Disturbance Rejection Control Theory}

The structure of LADRC is shown in Figure 3. LADRC is composed of tracking differentiator (TD), linear extended state observer (LESO), and linear state error feedback control law (LSEF). TD can not only overcome the interference noise by obtaining differential signals, but also make reasonable arrangements for the transition process. In other words, TD realizes the fast tracking of reference signal without overshoot and gives the tracking signals of all-order derivatives of reference signal. LESO is based on the development of the traditional observer, which takes the input and output of the control object as one of its inputs. The all-order derivatives of the plant state and the total disturbance variables can be observed through LESO. An obvious advantage of ESO is that it does not rely on the detailed mathematical model for generating disturbances, nor does it need to measure its role directly. LSEF generates the control signal using the output error between the TD and LESO. The mathematical description of one-order LADRC is shown as followings.
One-order TD is

$$
\frac{d z_{11}}{d t}=k_{0}\left(x_{1}^{r e f}-z_{11}\right)
$$

where $z_{11}$ is the tracking signal of reference input $x_{1}^{r e f}$.

Two-order LESO is

$$
\left\{\begin{array}{l}
\frac{d z_{21}}{d t}=z_{22}+k_{21} \varepsilon_{1}+u \\
\frac{d z_{22}}{d t}=k_{22} \varepsilon_{1} \\
\varepsilon_{1}=x_{1}-z_{21}
\end{array}\right.
$$

where $z_{21}$ is the estimated value of the plant state $x_{1} . z_{22}$ is the estimated value of the whole disturbance, which including $w(t)$ and other parameter uncertainties. $k_{21}$ and $k_{22}$ are gain coefficients.

LSEF control law is

$$
u=-z_{22}+k\left(z_{11}-z_{21}\right)
$$

where $k$ are the gain coefficient.

Eq. 21 can be expressed as

$$
\left\{\begin{array}{l}
2 L_{s} \frac{d \widehat{i_{d}}}{d t}=f_{d}-\widehat{u_{d}^{*}} \\
2 L_{s} \frac{d \widehat{i_{q}}}{d t}=f_{q}-\widehat{u_{q}^{*}}
\end{array}\right.
$$

Where $\quad f_{d}=-2 \omega L \widehat{i_{q}}-u_{g d}-\frac{v_{\text {eqc }}-v_{\text {eqc }}^{*}}{v_{\text {eqc }}^{*}} \widehat{u_{d}^{*}}, \quad f_{q}=2 \omega L \widehat{i_{d}}-u_{g q}-$ $\frac{v_{\text {eqc }}-v_{\text {eqc }}^{*}}{v_{\text {eqc }}^{*}} \widehat{u_{q}^{*}} \cdot f_{d}$ and $f_{q}$ are nonlinear and difficult to measure accurately. According to the LADRC theory, $f_{d}$ and $f_{q}$ can be regarded as the total disturbances and estimated by the LESO. So the dynamics of $\hat{i_{d}}$ and $\hat{i_{q}}$ can be decoupled to two independent subsystems based on LADRC. Then we can design the ac power decoupling control structure as Figure 4, which is divided into MMC valve level controller, MMC inner controller and MMC outer controller. The MMC valve level controller contains the modulation strategy and capacitor voltage balancing control,etc. The phase-shifted carrier PWM strategy is adopted, which is calculated based on the virtual resistor and the reference value of DC-bus voltage. The inner controller is core point of decoupling controller, which is designed based on LADRC. The outer controller can receive active power and reactive power commands from power dispatch center.

\section{SMALL-SIGNAL STABILITY ANALYSIS OF MODULAR MULTILEVEL CONVERTER BASED THREE-TERMINAL AC/DC DISTRIBUTION NETWORK}

Tangjiawan town is located in Zhuhai city, China. With the continuous progress of industrial park, the load of Tangjiawan town has increased too fast. If only Tangjiawan station supplies power, the power supply radius will be too long, the reliability is low, and the line loss is high. In order to improve the power supply quality and reliability, two $10 \mathrm{kV}$ buses are introduced 


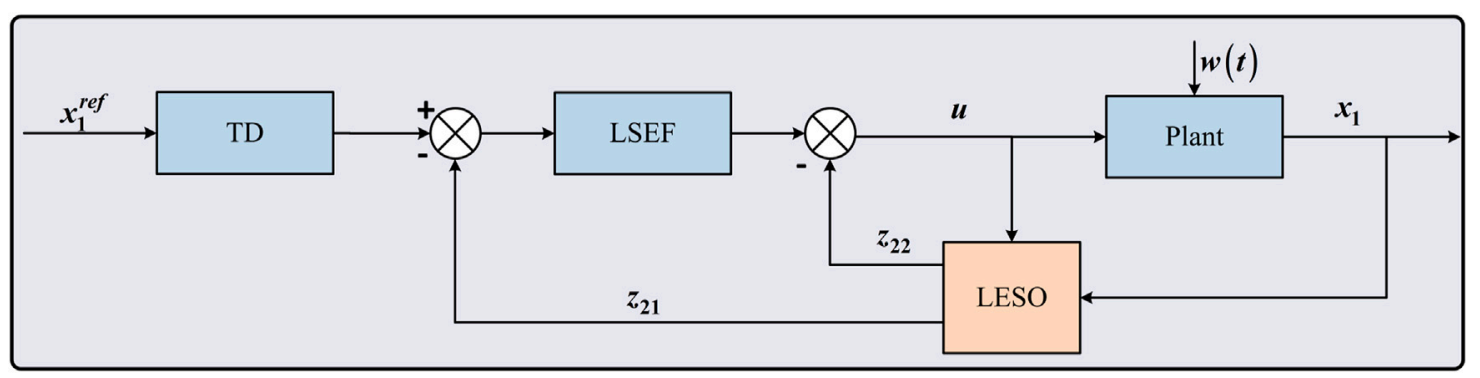

FIGURE 3 | Structure of LADRC.

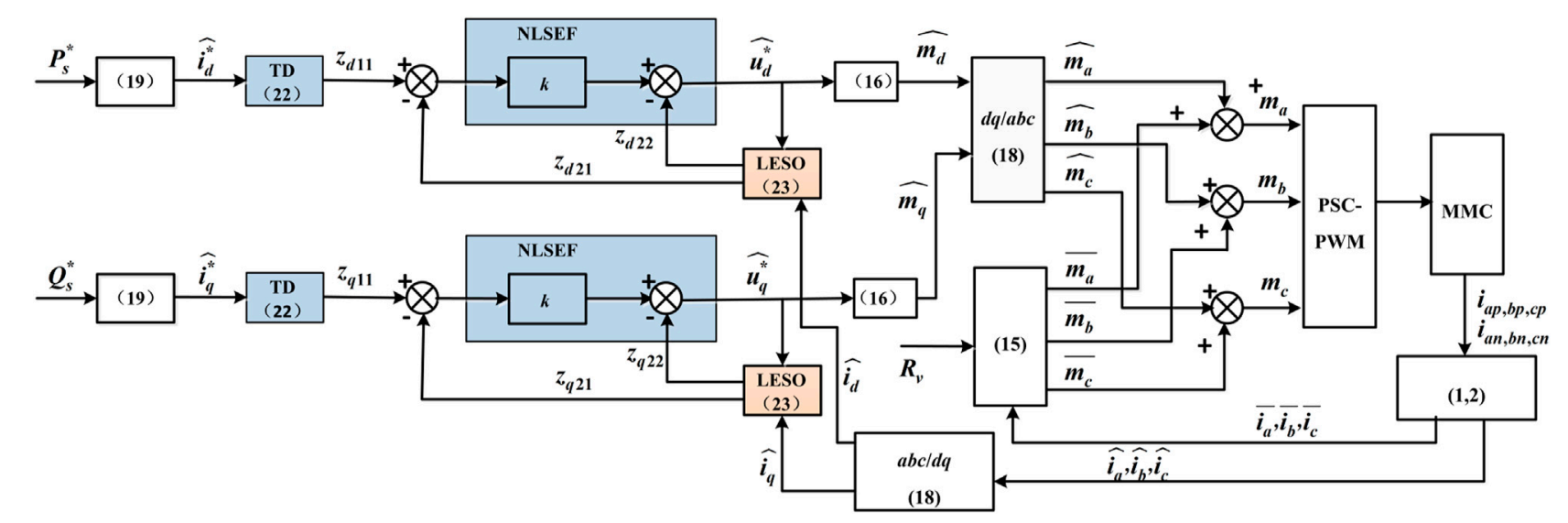

FIGURE 4 | Power decoupling control diagram of MMC.

from Jishan station and connected with the $10 \mathrm{kV}$ bus of Tangiiawan station, so as to increase the load transfer capacity of Tangiiawan station and reserve capacity of grid accident. The topology of Tangjiawan-Jishan1 -Jishan2 AC/DC distribution network demonstration project is shown in Figure 5. The rated capacity of Tangjiawan, Jishan1, and Jishan2 station is 20,10 , and 10 MVA individually. The rated DC-bus voltage is $\pm 10 \mathrm{kV}$ and the rated AC voltage is $10.5 \mathrm{kV}$.

Although MMC has the same hardware topology, it can work as power station or voltage station. So the operation mode of MMC based three-terminal AC/DC distribution network is versatile. In this paper, the master-slave operation mode is studied according to the engineering application, that is, Tangjiawan Station is voltage station and Jishanl and Jishan two stations are power stations. The instantaneous-value model of MMC is too complicated to the small-signal stability analysis. In order to simplify the analysis, averaged-value model is needed.

\subsection{Averaged-Value Model of Modular Multilevel Converter Power Station}

According to Eq. 14, the differential-mode component of capacitor voltage is ac variables and can be neglected based on the switching period. The common-mode component of capacitor voltage is balanced, that is

$$
\overline{v_{a p c}}=\overline{v_{a n c}}=\overline{v_{b p c}}=\overline{v_{b n c}}=\overline{v_{c p c}}=\overline{v_{c n c}}=v_{e q c}
$$

When common-mode component of arm current is balanced, there is

$$
\overline{i_{j}}=\frac{i_{d c}}{3}
$$

According to Eqs 7, 9, 12, 26, 27 and the law of energy conservation, the state equation of the equivalent capacitance is

$$
C_{e q} v_{e q c} \frac{d v_{e q c}}{d t}=i_{d c} v_{e q c}+\frac{2 R_{v} v_{e q c}}{3 V_{e q c}^{*}} i_{d c}^{2}+P_{g}
$$

where the equivalent capacitance $C_{e q}=6 \mathrm{C} / \mathrm{N}$ and $P_{g}$ is AC active power controlled by LADRC.

According to Eqs 6, 9, 12, 26, 27, the state equation of the DC current

$$
2 L_{0} \frac{d i_{d c}}{d t}=3 u_{d c}-3 v_{e q c}-\frac{2 R_{v} v_{e q c}}{v_{e q c}^{*}} i_{d c}
$$

The linearized model of the Eqs 28 and 29 is

$$
\left\{\begin{array}{l}
2 L_{0} \frac{d \Delta i_{d c}}{d t}=3 \Delta u_{d c}-3 \Delta v_{e q c}-\frac{2 R_{v}}{v_{\text {eqc }}^{*}} v_{e q 0} \Delta i_{d c}-\frac{2 R_{v}}{v_{\text {eqc }}^{*}} i_{d c 0} \Delta v_{e q c} \\
C_{e q} v_{e q 0} \frac{d \Delta v_{e q c}}{d t}=v_{e q 0} \Delta i_{d c}+i_{d c 0} \Delta v_{e q c}+\frac{4 R_{v}}{3 v_{\text {eqc }}^{*}} i_{d c} v_{e q 0} \Delta i_{d c}+\frac{2 R_{v}}{3 v_{\text {eqc }}^{*}} i_{d c 0}^{2} \Delta v_{e q c}+\Delta P_{g}
\end{array}\right.
$$




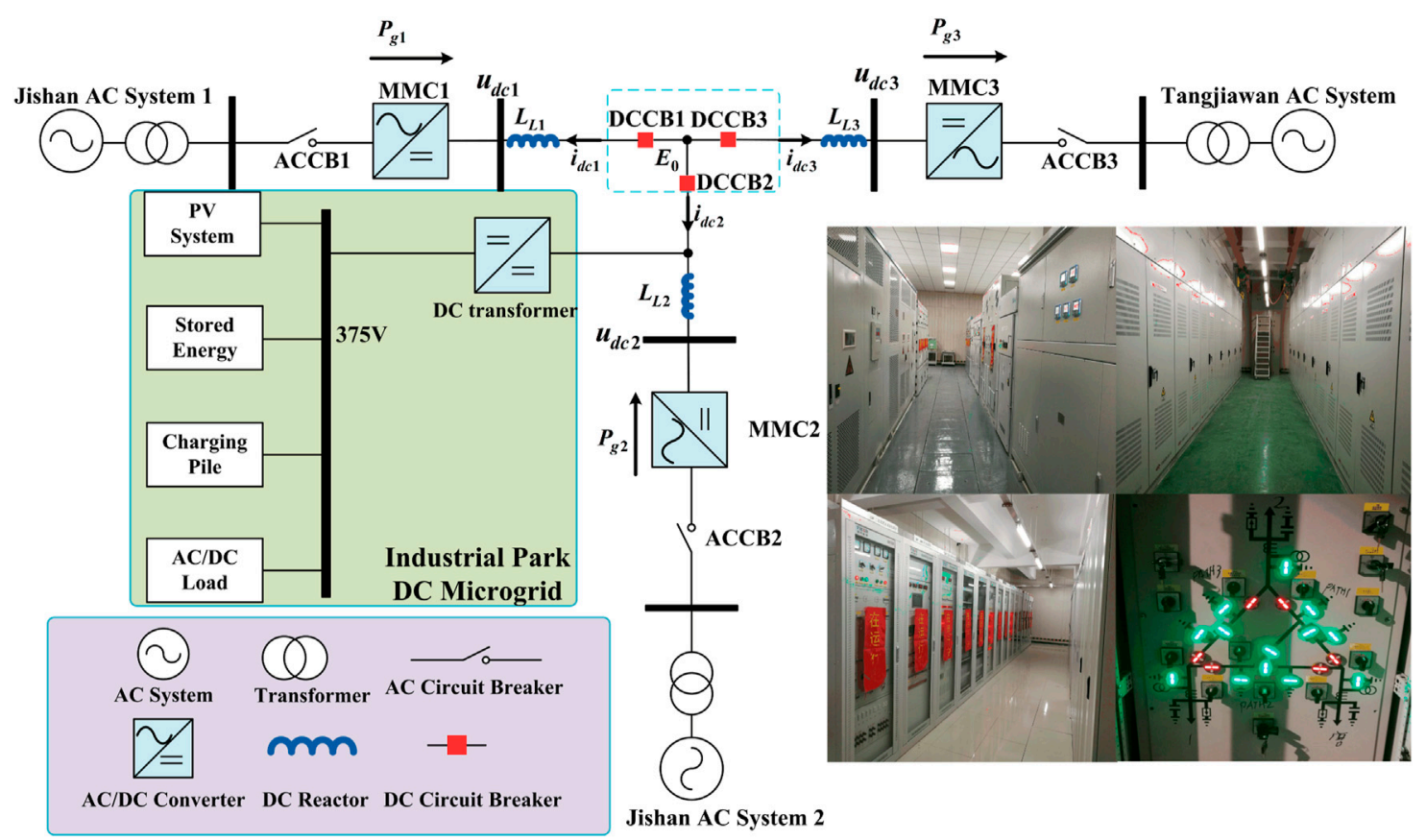

FIGURE 5 | Topology of Tangjiawan-Jishan1-Jishan2 AC/DC distribution network.

where $v_{e q c 0}$ and $i_{e q c 0}$ are the steady-state operating points satisfying the following equations.

$$
\left\{\begin{array}{l}
0=3 u_{d c 0} v_{\mathrm{eq} c}^{*}-3 v_{e q c 0} v_{\mathrm{eqc}}^{*}-2 R_{v} v_{e q c 0} i_{d c 0} \\
0=3 v_{\mathrm{eq} c}^{*} i_{d c 0} v_{e q c 0}+2 R_{v} v_{e q c 0} i_{d c 0}^{2}+P_{g 0}
\end{array}\right.
$$

4.1.1 $R_{v}=0$

When the virtual resistance is 0 , the equilibrium point is

$$
\left\{\begin{array}{l}
i_{d c 0}=\frac{P_{g 0}}{u_{d c 0}} \\
v_{e q c 0}=u_{d c 0}
\end{array}\right.
$$

where $v_{\text {eqco }}$ is determined by the external DC voltage source. $i_{\text {eqc0 }}$ is determined according to the law of conservation of power. The different choices of $v_{e q c}^{*}$ don't affect the equilibrium points.

\subsection{2 $R_{v} \neq 0$}

When the virtual resistance is nonzero, the equilibrium point is

$$
\left\{\begin{array}{l}
i_{d c 0}=\frac{-\left(2 R_{v} P_{\mathrm{g} 0}+3 u_{d c 0} v_{e q c}^{*}\right)+\sqrt{4 R_{v}^{2} P_{g 0}^{2}+9 u_{d c 0}^{2} v_{e q c}^{*} 2-12 u_{d c 0} R_{v} v_{e q c}^{*} P_{\mathrm{g} 0}}}{4 u_{d c 0} R_{v}} \\
v_{e q c 0}=\frac{3 u_{d c 0} v_{e q c}^{*}}{3 v_{e q c}^{*}+2 R_{v} i_{d c 0}}
\end{array}\right.
$$

where $v_{e q c}^{*}$ and $R_{v}$ affect the equilibrium point. The characteristic equations of the system Eq. 30 is

$$
a_{2} s^{2}+a_{1} s+a_{0}=0
$$

where $a_{2}=3 L_{0} C_{e q} v_{e q c}^{*} v_{e q c 0}, a_{1}=f(x)=3 v_{e q c 0}^{2} C_{e q} R_{v}-2 L_{0} i_{d c 0}^{2} R_{v}-$ $3 L_{0} i_{d c 0} v_{e q c}^{*}, a_{0}=v_{e q c 0}\left(3 v_{e q c}^{*}+2 i_{d c 0} R_{v}\right)^{2}$. According to the Routh criterion, the MMC power station is stable only when the following equation is satisfied

$$
\left\{\begin{array}{l}
f(x)>0 \\
R_{v} \neq-\frac{1.5 v_{\mathrm{eqc}}^{*}}{i_{d c 0}}
\end{array}\right.
$$

So the stable region is that $R_{v}>3 L_{0} i_{d c 0} v_{e q c}^{*} /\left(3 v_{e q c 0}^{2} C_{e q}-\right.$ $\left.2 L_{0} i_{d c 0}^{2}\right)$ and $R_{v} \neq-1.5 v_{e q c}^{*} / i_{d c 0}$.

\subsection{Small-Signal Stability Analysis of Three-Terminal Modular Multilevel \\ Converter Based DC Grid}

The nodal equation of DC network is

$$
\left\{\begin{array}{c}
L_{L 1} \frac{d i_{d c 1}}{d t}=E_{0}-u_{d c 1} \\
L_{L 2} \frac{d i_{d c 2}}{d t}=E_{0}-u_{d c 2} \\
L_{L 3} \frac{d i_{d c 3}}{d t}=E_{0}-u_{d c 3} \\
i_{d c 1}+i_{d c 2}+i_{d c 3}=0
\end{array}\right.
$$

where $L_{L 1}, L_{L 2}, L_{L 3}$ are the DC line inductors and $E_{0}$ is the nodal voltage at the common connection point.

The relationship between voltage and current of MMC3 is

$$
E_{0}=L_{L 3} \frac{d i_{d c 3}}{d t}+E
$$




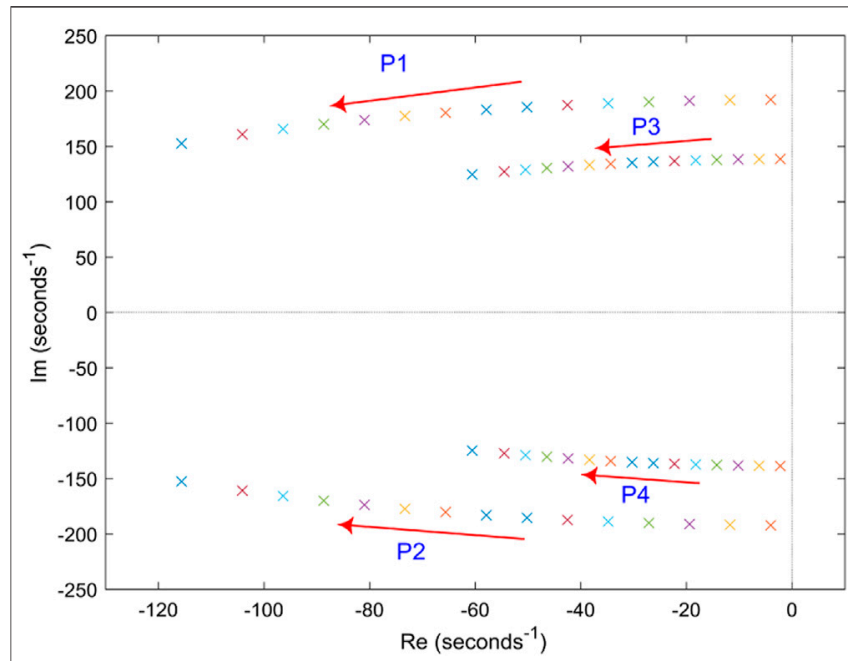

FIGURE 6 | Root locus with increase of $R_{v}$.

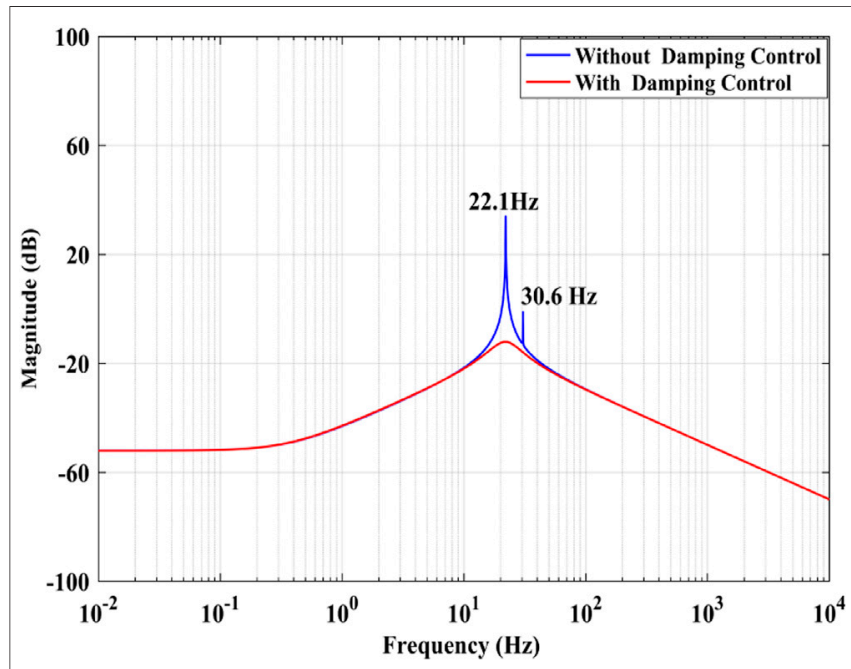

FIGURE 7 | Bode diagram of $\Delta i_{d c 3} / \Delta P_{g 1}\left(R_{v}=1\right)$.

where $E$ is the terminal voltage of $\mathrm{MM} 3$, the output voltage control can be seen in (Li et al., 2018) and is not discussed in detail in this paper.

According to (Eq. 30, 36, 37), the linearization model of threeterminal MMC based DC grid is

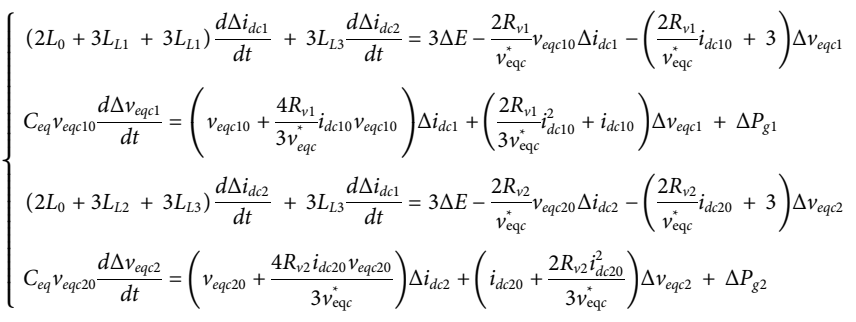

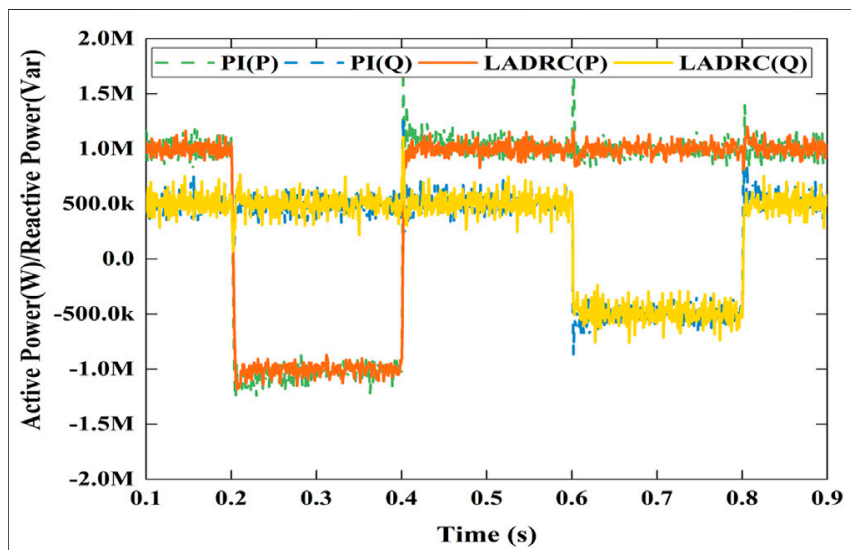

FIGURE 8 | Active power and reactive power.

The operation condition is that active power of MMC1 is $-2 \mathrm{MW}$ and that of MMC2 is $1 \mathrm{MW}$, the arm inductor is $7 \mathrm{mH}$ and DC inductor is $4 \mathrm{mH}$. Figure 6 shows the root locus. there are two pairs of conjugate complex roots in the left half plane. With the increase of $R_{v}$, the roots gradually moves away from the virtual axis, which indicates that $R_{v}$ can enhance the stability of DC grid.

Figure 7 shows the amplitude frequency characteristics of the transfer function $\Delta i_{d c 3} / \Delta P_{g 1}$. When there is no virtual resistor, there are two low frequency resonance points in bode diagram, which are 22.1 and $30.6 \mathrm{~Hz}$ respectively. The resonance peak value at $22.1 \mathrm{~Hz}$ is obviously higher than that at $30.6 \mathrm{~Hz}$. So the main resonance frequency of DC grid is about $22.1 \mathrm{~Hz}$. When the virtual resistor is added, the resonance peak value attenuates greatly. Virtual resistor can effectively suppress the system oscillation and improve the transient performance of DC grid.

\section{SIMULATIONS OF MODULAR MULTILEVEL CONVERTER BASED THREE-TERMINAL AC/DC DISTRIBUTION NETWORK}

The number of sub-modules $N=25$. The sub-module capacitance is $13 \mathrm{mF}$ and the switching frequency is $300 \mathrm{~Hz}$. The phase leg reactor is $7 \mathrm{mH}$ and the rated voltage of $\mathrm{AC}$ and $\mathrm{DC}$ are $10 \mathrm{kVac}$ and $20 \mathrm{kVdc}$ individually. PSC-PWM is adopted and the electromagnetic transient model of MMC based three-terminal $\mathrm{AC} / \mathrm{DC}$ distribution network is established on PSCAD.

Figures 8-13 shows the decoupling power control of MMC under LADRC and PI controller. Figure 8 shows the simulation results of active power step response. Active power immediately responds step disturbance and changes from $1 \mathrm{MW}$ to $-1 \mathrm{MW}$ at $0.2 \mathrm{~s}$ and changes from -1 to $1 \mathrm{MW}$ at $0.4 \mathrm{~s}$. Reactive power also instantly responds step disturbance and varies from 0.5 Mvar to -0.5 Mvar at $0.6 \mathrm{~s}$ and varies from -0.5 Mvar to 0.5 Mvar at $0.8 \mathrm{~s}$. Obviously, it results in a little 


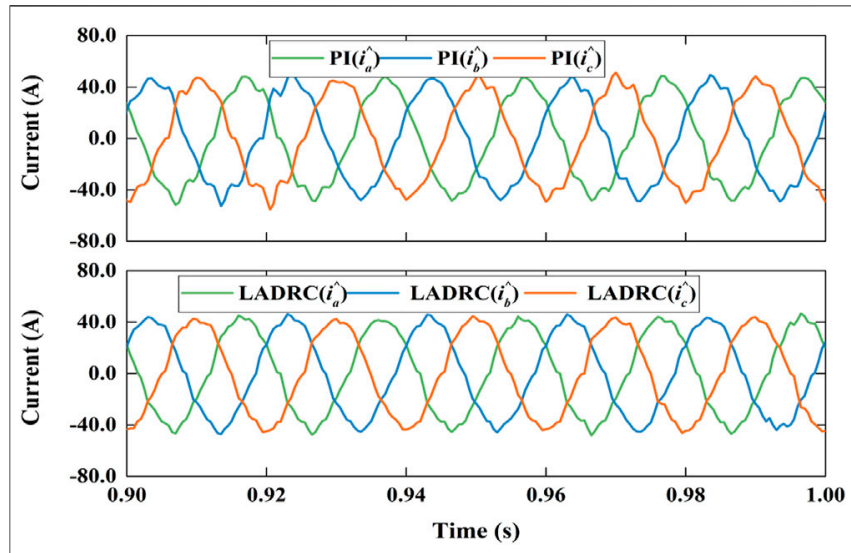

FIGURE 9 | Differential-mode component of arm current.

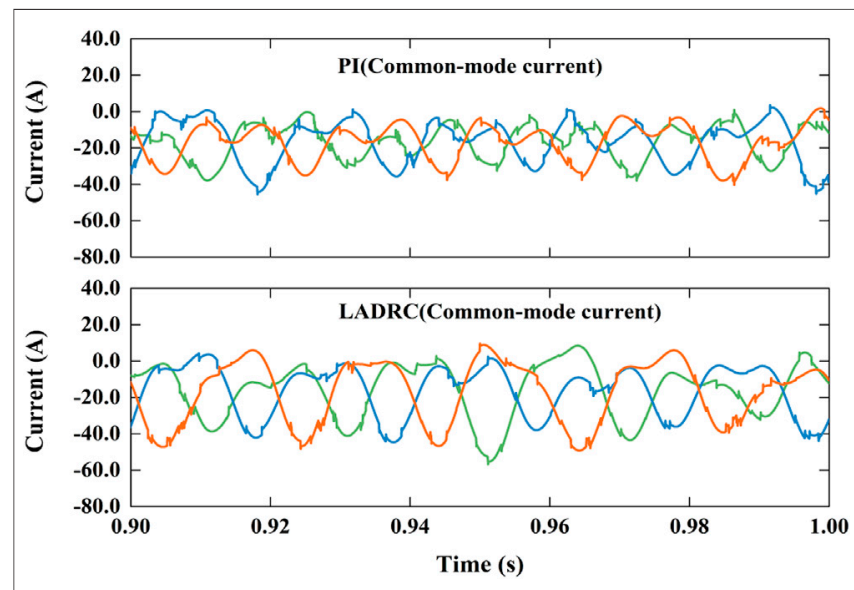

FIGURE 10 | Common-mode component of arm current.

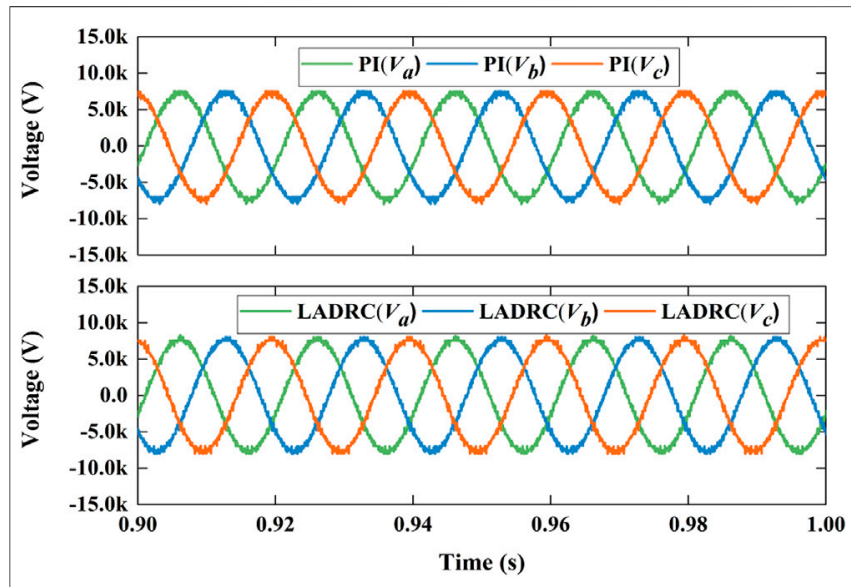

FIGURE 11 | AC voltage of MMC.

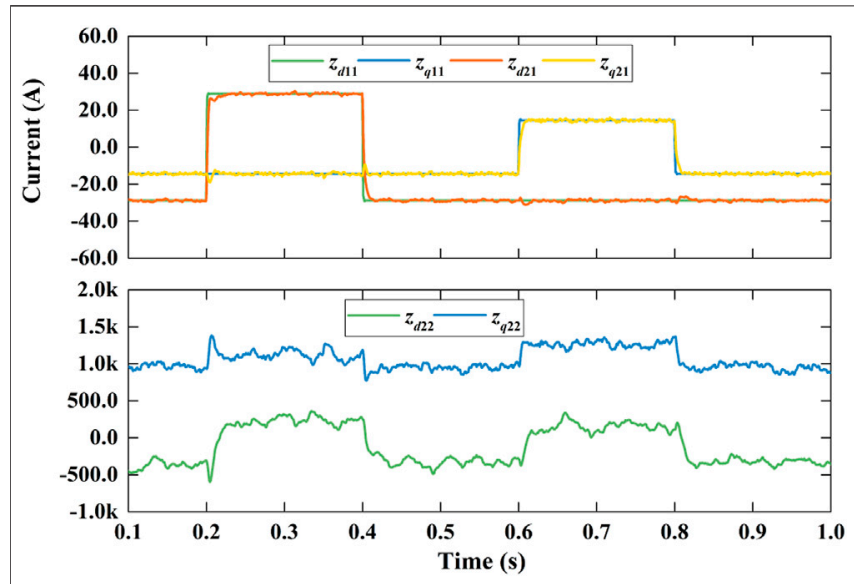

FIGURE 12 | State variables of LADRC.

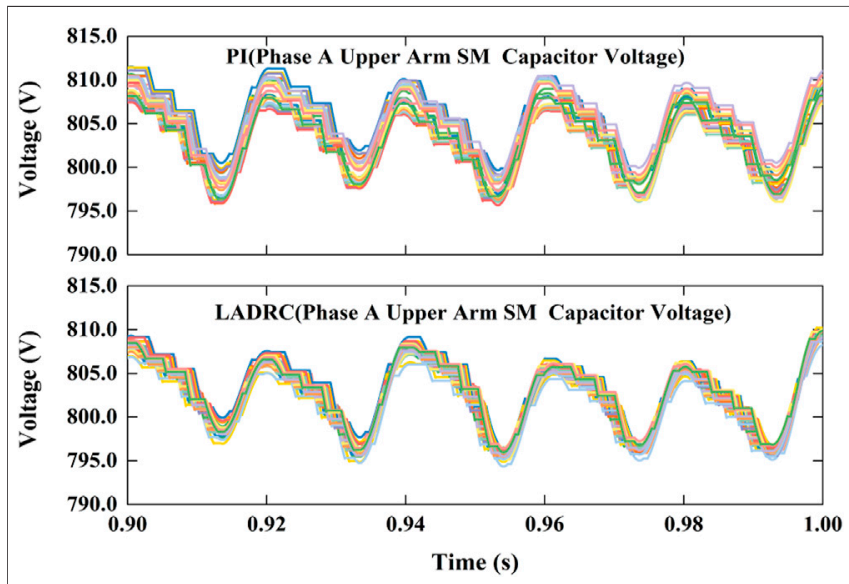

FIGURE 13 | Sub-module capacitor voltage.

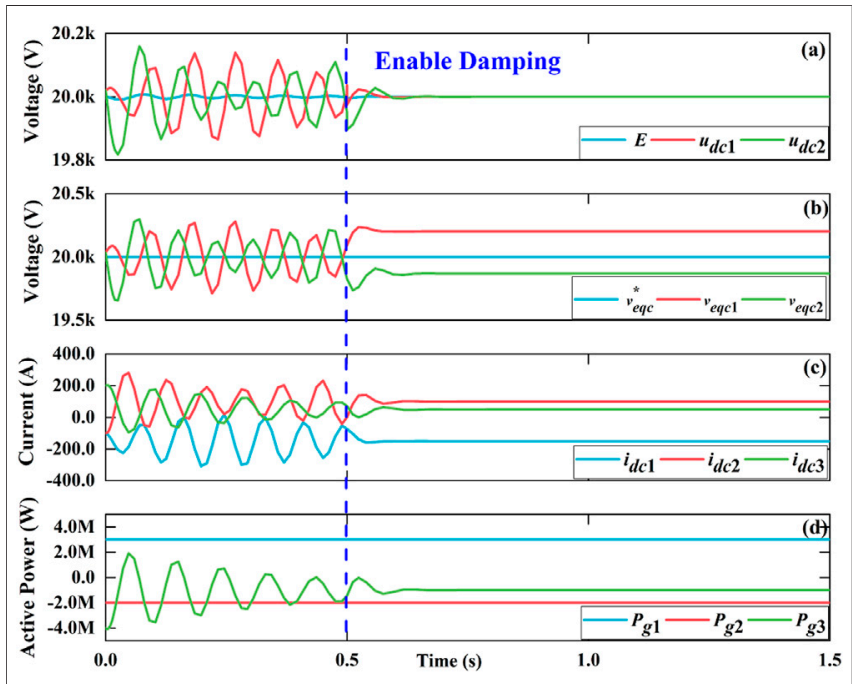

FIGURE 14 | Variables of MMC based three-terminal DC grid $\left(R_{v}=1\right)$. 


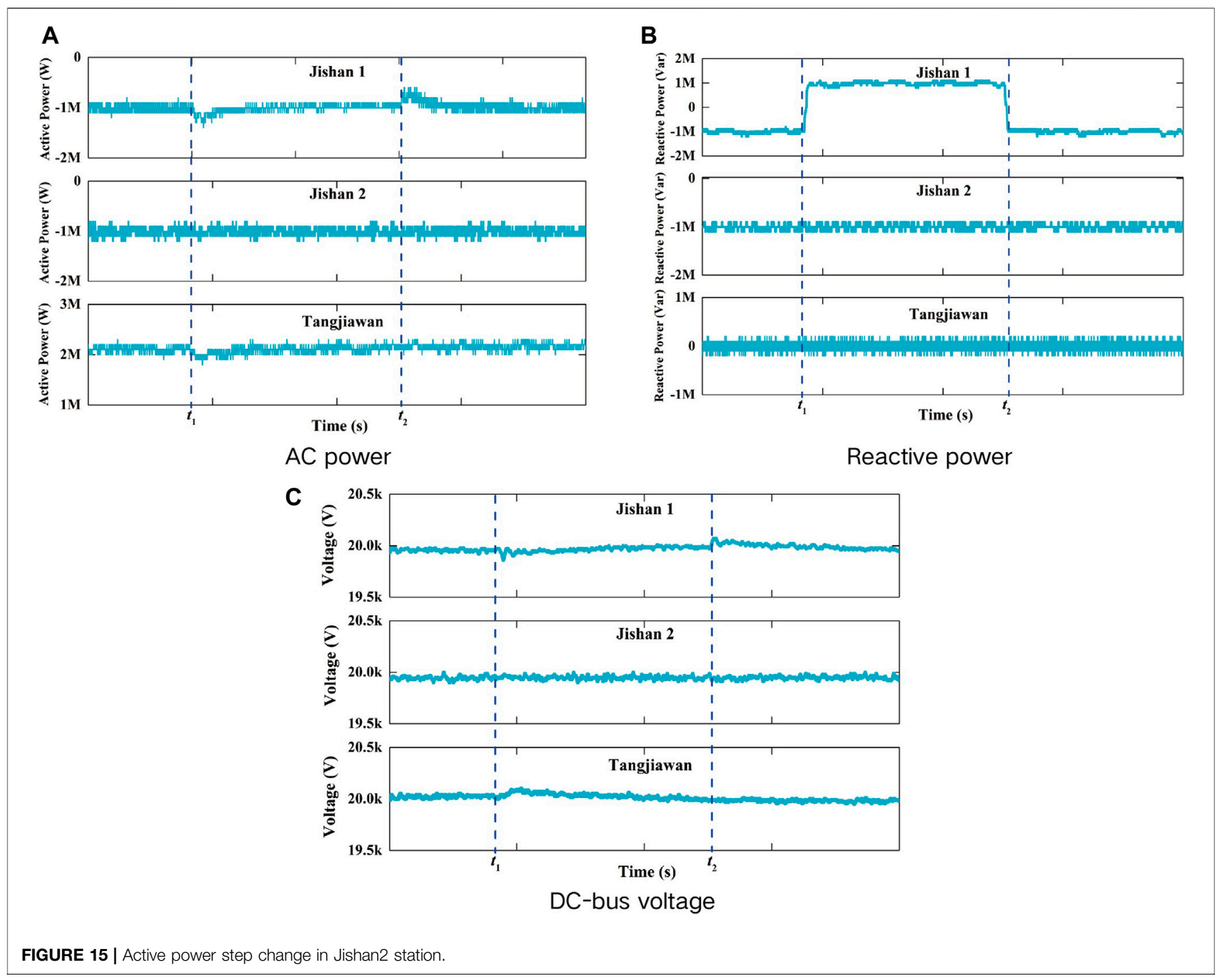

fluctuations when step disturbance occurs momentarily. Figure 9 is the differential-mode component of arm current which has waveform aberration. Figure $\mathbf{1 0}$ are the common-mode component of arm current with a little more waveform burred. As shown in Figure 11, The each phase peak AC voltage output of MMC has reached at about $8.17 \mathrm{kV}$.Figure 12 shows the derivatives of LADRC. $Z_{d 22}$ and $Z_{q 22}$ are estimated of total system disturbances. Figure 13 is the sub-module capacitor voltages, which is balanced and the capacitor voltage difference is less than $1.2 \%$. In briefly, the simulation results reveal that LADCR can successfully realize the decoupling control of AC active power and reactive power. Compared with PI controller, LADRC has the advantages of smoother power waveform, faster response and lower overshoot, etc.

Figure 14 shows variables of MMC based three-terminal DC grid. When there is no virtual resistor, there exists continuous oscillation in DC-bus voltage, DC current, capacitor voltage and active power because of lack of damping. When virtual resistor is added at $t=0.5 \mathrm{~s}$, the oscillation can be suppressed quickly and the DC-bus voltage can be stabilized at $20 \mathrm{kV}$. When virtual resistor is added, the stable capacitor voltage is determined by the active power.

\section{EXPERIMENTS ON TANGJIAWAN-JISHAN1-JISHAN2 AC/DC DISTRIBUTION NETWORK}

\subsection{Active Power Step Test of Jishan2 Station}

Figure 15 shows system waveforms with active power step change in Jishan2 station. As shown in Figure 15A, active power of Jishan1 station is constant at $-1 \mathrm{MW}$. Active power of Jishan2 station changes from -1 to $1 \mathrm{MW}$ at $t_{1}$, and from $1 \mathrm{MW}$ to $-1 \mathrm{MW}$ at $t_{2}$. Accordingly, active power of Tangjiawan station changes from 2 to $0 \mathrm{MW}$ at $t_{1}$, and from 0 to $2 \mathrm{MW}$ at $t_{2}$. Reactive power of Jishan1 remains 1 MVar. There are fluctuations in reactive power of Jishan2 station and Tangjiawan station at the moment of active power 

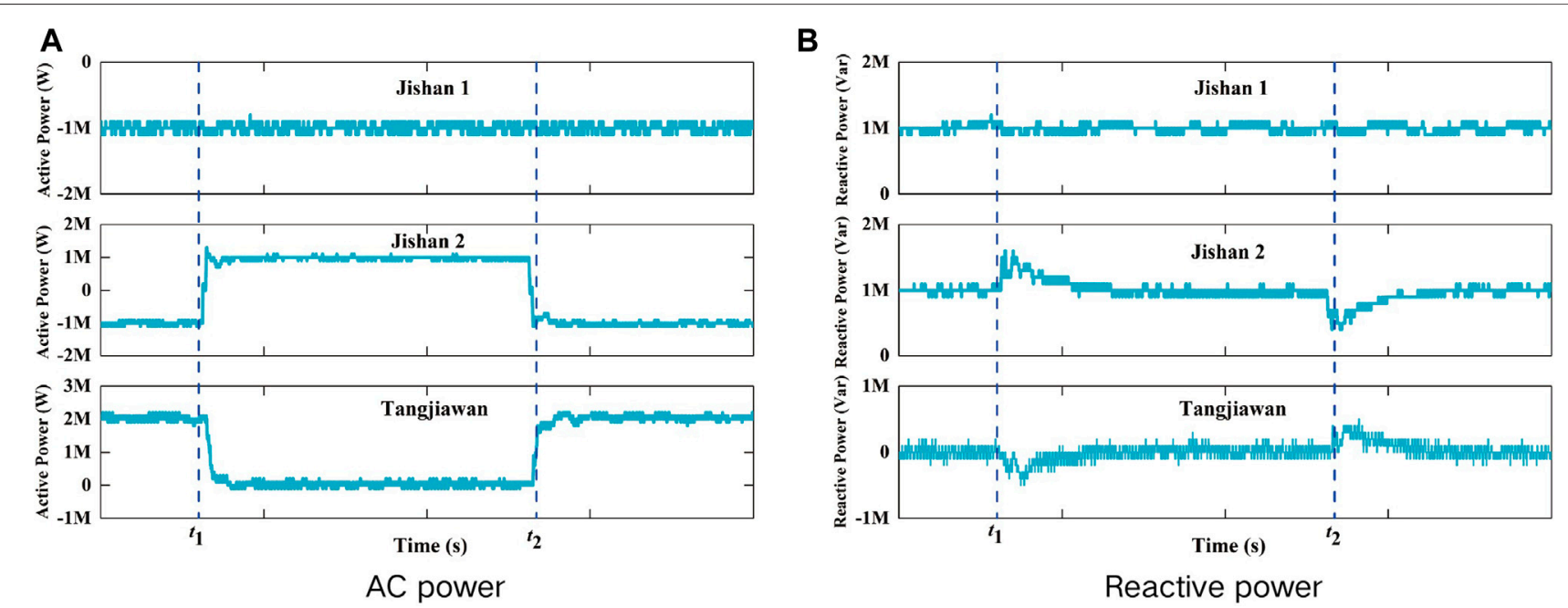

AC power

Reactive power

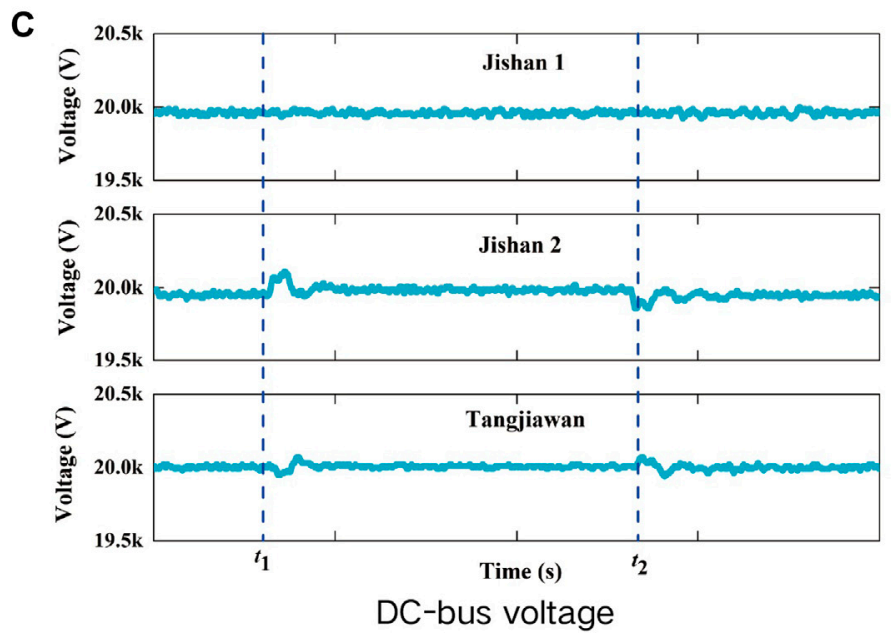

FIGURE 16 | Reactive power step change in Jishan1 station.

change. But reactive power of Jishan2 and Tangjiawan will remain stable at $1 \mathrm{Mvar}$ and $0 \mathrm{Mvar}$ when active power is stable as shown in Figure 15B. Figure 15C shows the DC-bus voltage. The DC-bus voltage of Tangjiawan station is constant at $20 \mathrm{kV}$. There exist slight fluctuations in DC-bus voltages of Jishan1 station and Jishan2 station at the moment of active power change, but the DC-bus voltages still are within the reasonable range.

\subsection{Reactive Power Step Test of Jishan1 Station}

Figure 16 shows the system waveforms with reactive power step change in Jishan1 station. As shown in Figure 16A, active power of Jishan1 station, Jishan2 station, and Tangjiawan station is constant at $-1,-1$, and $2 \mathrm{MW}$ respectively. Figure 16B shows that reactive power of Jishan1 station changes from -1Mvar to $1 \mathrm{Mvar}$ at $t_{1}$, and changes from 1 to -1 Mvar at $t_{2}$. Reactive power of Jishan2 station and Tangjiawan station remains unchanged at -1Mvar and 0Mvar individually. Figure 16C shows that the reactive power step change of Jishan1 has influence on the DC-bus voltages of Jishan1 station and Tangjiawan station, but the DC-bus voltage is still within the reasonable range.

\subsection{Active Power Flow Reversal Test of Jishan1 Station}

Figure $\mathbf{1 7}$ is the experiments results of active power reversal test of Jishan 1 station. Figure 17A shows that Jishan2 station active power still remains $1 \mathrm{MW}$ when Jishan 1 station active power flow reversal starts at $t_{1}$ and completes at $t_{2}$ with active power varies from 1 to $-1 \mathrm{MW}$. However, Tangjiawan station active power responds flow reversal immediately with active power varies from -2 to $0 \mathrm{MW}$. Figure 17B shows that active power flow reversal can influence reactive power of Jishan 1 and Tangjiawan station, but the reactive power of Jishan 1 station and Tangjiawan station still remains $1 \mathrm{Mvar}$ and 0 Mvar respectively with waveform burr increased. 


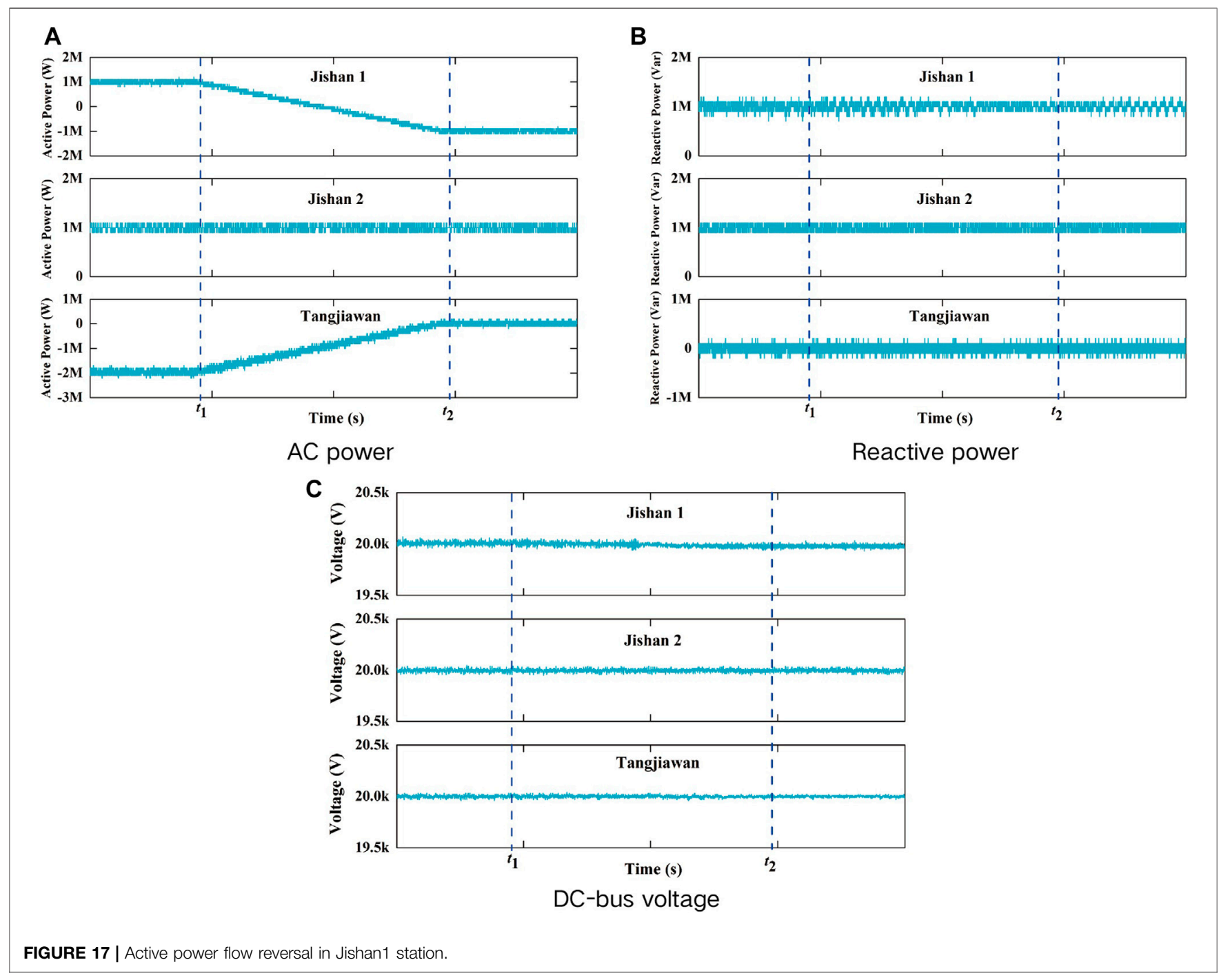

Figure 17C shows that DC bus voltage of three converters station is stable at $20 \mathrm{kV}$, but Jishan 1 station DC bus voltage fluctuates a little bit more than other two stations.

\section{CONCLUSION}

A novel instantaneous-value model of MMC is derived by introducing the differential-mode and common-mode component representation. Then, ac power modeling of MMC is established based on the PSC-PWM strategy and power decoupling control based on LADRC is realized. Simplified average-value model of MMC power station is deduced and the small signal stability analysis of three-terminal DC grid is carried out. Simulation and experiment results of the Tangiiawan-Jishan1-Jishan2 AC/DC distribution network demonstration project verify that the power decoupling strategy based on LADRC is better than PI controller. The virtual resistor can greatly improve the transient performance and system stability. The modeling and analysis method proposed in this paper is concise and effective. The research of this paper is the expansion of MMC application in the field of distribution network. MMC based multi-terminal AC/DC distribution network can realize the multidirectional power flow among AC-grids, which can greatly improve the power supply reliability.

\section{DATA AVAILABILITY STATEMENT}

The raw data supporting the conclusion of this article will be made available by the authors, without undue reservation.

\section{AUTHOR CONTRIBUTIONS}

ZX and HY: conceptualization, data curation, methodology and writing. GZ and LL: formal analysis and simulation study. PW and CJ: reagents/materials/analysis. 


\section{FUNDING}

This journal was supported in part by Natural Science Foundation of Guangdong Province under Grant (2018A0303130111), in part by Open Project of Anhui Key Laboratory of Intelligent Building and Building Energy Saving under Grant (IBES2020KF10), in part by the Guangzhou Science and Technology Planning Project under

\section{REFERENCES}

Adam, G. P., and Williams, B. W. (2014). Half- and Full-Bridge Modular Multilevel Converter Models for Simulations of Full-Scale HVDC Links and Multiterminal DC Grids. IEEE J. Emerg. Sel. Top. Power Electron. 2 (4), 1089-1108. doi:10.1109/jestpe.2014.2315833

Ahmed, N., Angquist, L., Mehmood, S., Antonopoulos, A., Harnefors, L., Norrga, S., and Nee, H. (2016). "Efficient Modeling of an Mmc-Based Multiterminal Dc System Employing Hybrid Hvdc Breakers," in 2016 IEEE Power and Energy Society General Meeting (PESGM), Boston, MA, July 17-21, 2016, 1. doi:10.1109/pesgm.2016.7741765

Alassi, A., Bañales, S., Ellabban, O., Adam, G., and MacIver, C. (2019). Hvdc Transmission: Technology Review, Market Trends and Future Outlook. Renew. Sustain. Energ. Rev. 112, 530-554. doi:10.1016/j.rser.2019.04.062

Alonge, F., Cirrincione, M., D'Ippolito, F., Pucci, M., and Sferlazza, A. (2017). Active Disturbance Rejection Control of Linear Induction Motor. IEEE Trans. Ind. Applicat. 53 (5), 4460-4471. doi:10.1109/tia.2017.2697845

Angquist, L., Antonopoulos, A., Siemaszko, D., Ilves, K., Vasiladiotis, M., and Nee, H.-P. (2011). Open-Loop Control of Modular Multilevel Converters Using Estimation of Stored Energy. IEEE Trans. Ind. Applicat. 47 (6), 2516-2524. doi:10.1109/tia.2011.2168593

Antonopoulos, A., Angquist, L., and Nee, H. P. (2009). "On Dynamics and Voltage Control of the Modular Multilevel Converter," in 2009. EPE '09. 13th European Conference on, Barcelona, Spain, September 8-10, 2009 (Power Electronics and Applications).

Bergna Diaz, G., Suul, J. A., and D’Arco, S. (2015). "Small Signal State-Space Modeling of Modular Multilevel Converters for System Stability Analysis," in 2015 IEEE Energy Conversion Congress and Exposition (ECCE), Montreal, Canada, September 20-24, 2015, 5822-5829. doi:10.1109/ecce.2015.7310477

Chen, Y. C., Dhople, S. V., Guggilam, S. S., Dall'Anese, E., and Giannakis, G. B. (2016). Scalable Optimization Methods for Distribution Networks with High Pv Integration. IEEE Trans. Smart Grid 7 (4), 2061-2070. doi:10.1109/TSG.2016.2543264

Chen, W.-H., Yang, J., Guo, L., and Li, S. (2016). Disturbance-Observer-Based Control and Related Methods-An Overview. IEEE Trans. Ind. Electron. 63 (2), 1083-1095. doi:10.1109/tie.2015.2478397

Debnath, S., Qin, J., Bahrani, B., Saeedifard, M., and Barbosa, P. (2015). Operation, Control, and Applications of the Modular Multilevel Converter: A Review. IEEE Trans. Power Electron. 30 (1), 37-53. doi:10.1109/ tpel.2014.2309937

Friedrich, K. (2010). "Modern Hvdc Plus Application of Vsc in Modular Multilevel Converter Topology," in 2010 IEEE International Symposium on Industrial Electronics, Bari, Italy, July 4-7, 2010, 3807-3810. doi:10.1109/ isie.2010.5637505

Guan, M., and Xu, Z. (2012). Modeling and Control of a Modular Multilevel Converter-Based Hvdc System under Unbalanced Grid Conditions. IEEE Trans. Power Electron. 27 (12), 4858-4867. doi:10.1109/tpel.2012.2192752

Harnefors, L., Antonopoulos, A., Norrga, S., Angquist, L., and Nee, H.-P. (2013). Dynamic Analysis of Modular Multilevel Converters. IEEE Trans. Ind. Electron. 60 (7), 2526-2537. doi:10.1109/tie.2012.2194974

Kotb, O., Ghandhari, M., Eriksson, R., and Sood, V. K. (2016). On Small Signal Stability of an Ac/dc Power System with a Hybrid Mtdc Network. Electric Power Syst. Res. 136, 79-88. doi:10.1016/j.epsr.2016.02.004

Lesnicar, A., and Marquardt, R. (2004). "An Innovative Modular Multilevel Converter Topology Suitable for a Wide Power Range," in Power Tech Conference, Bologna, Italy, June 23-26, 2003.
Grant (201902020003), in part by the Guangdong Special Project in Key Field of Artificial Intelligence for Ordinary University under Grant (2019KZDZX1004), in part by the Guangzhou Key Laboratory Project of Intelligent Building Equipment Information Integration and Control under Grant (202002010003), in part by the Guangzhou Yuexiu District Science and Technology Plan Major Project under Grant (2019-GX-010).

Li, Y., Tang, G., Ge, J., He, Z., Pang, H., Yang, J., et al. (2018). Modeling and Damping Control of Modular Multilevel Converter Based Dc Grid. IEEE Trans. Power Syst. 33 (1), 723-735. doi:10.1109/tpwrs.2017.2691737

Li, Y., Liu, K., Liao, X., Zhu, S., Huai, Q., and Huai, Q. (2019). A Virtual Impedance Control Strategy for Improving the Stability and Dynamic Performance of VSC-HVDC Operation in Bidirectional Power Flow Mode. Appl. Sci. 9 (15), 3184. doi:10.3390/app9153184

Liu, C., Luo, G., Wencong, T. U., and Wan, H. (2017). Servo Systems with Double Closed-Loops Based on Active Disturbance Rejection Controllers. Chin. Soc. Electr. Eng. 37 (23), 7032-7039. doi:10.13334/j.0258-8013.pcsee.161957

Liu, C., Luo, G., Duan, X., Chen, Z., Zhang, Z., and Qiu, C. (2020). Adaptive LADRC-Based Disturbance Rejection Method for Electromechanical Servo System. IEEE Trans. Ind. Applicat. 56 (1), 876-889. doi:10.1109/ tia.2019.2955664

Lu, X., Xiang, W., Lin, W., and Wen, J. (2018). Small-Signal Modeling of Mmc Based Dc Grid and Analysis of the Impact of Dc Reactors on the Small-Signal Stability. Int. J. Electr. Power Energ. Syst. 101, 25-37. doi:10.1016/ j.ijepes.2018.01.046

Marquardt, R. (2010). "Modular Multilevel Converter: An Universal Concept for Hvdc-Networks and Extended Dc-Bus-Applications," in The 2010 International Power Electronics Conference - ECCE ASIA, Sapporo, Japan, June 21-24, 2010, 502-507. doi:10.1109/ipec.2010.5544594

Marquardt, R. (2011). "Modular Multilevel Converter Topologies with Dc-Short Circuit Current Limitation," in IEEE International Conference on Power Electronics \& Ecce Asia, Jeju, Korea (South), May 30-June 3, 2011. doi:10.1109/icpe.2011.5944451

Mithulananthan, N., Shah, R., and Bansal, R. C. (2013). Oscillatory Stability Analysis with High Penetrations of Large-Scale Photovoltaic Generation. Energ. Convers. Manage. 65, 420-429. doi:10.1016/ j.enconman.2012.08.004

Rao, H. (2015). Architecture of Nan'ao Multi-Terminal VSC-HVDC System and its Multi-Functional Control. CSEE Power Energ. Syst. 1 (1), 9-18. doi:10.17775/cseejpes.2015.00002

Saad, H., Peralta, J., Dennetiere, S., Mahseredjian, J., Jatskevich, J., Martinez, J. A., et al. (2013). Dynamic Averaged and Simplified Models for Mmc-Based Hvdc Transmission Systems. IEEE Trans. Power Deliv. 28 (3), 1723-1730. doi:10.1109/tpwrd.2013.2251912

Trinh, N.-T., Zeller, M., Wuerflinger, K., and Erlich, I. (2016). Generic Model of MMC-VSC-HVDC for Interaction Study with AC Power System. IEEE Trans. Power Syst. 31 (1), 27-34. doi:10.1109/tpwrs.2015.2390416

Vasiladiotis, M., Cherix, N., and Rufer, A. (2014). Accurate Capacitor Voltage Ripple Estimation and Current Control Considerations for Grid-Connected Modular Multilevel Converters. IEEE Trans. Power Electron. 29 (9), 4568-4579. doi:10.1109/tpel.2013.2286293

Wan, X., Li, Y., and Peng, M. (2018). Modelling, Analysis and Virtual Parallel Resistor Damping Control of VSC-Based DC Grid Using Master-Slave Control Mode. IET Generation, Transm. Distribution 12 (9), 2046-2054. doi:10.1049/ iet-gtd.2017.1021

Wang, J., and Wang, P. (2019). Decoupled Power Control for Direct-ModulationBased Modular Multilevel Converter with Improved Stability. IEEE Trans. Ind. Electron. 66 (7), 5264-5274. doi:10.1109/tie.2018.2870352

Wang, P., Liu, X., and Loh, P. C. (2011). A Hybrid Ac/dc Microgrid and its Coordination Control. IEEE Trans. Smart Grid 2 (2), 278-286. doi:10.1109/ TSG.2011.2116162

Wang, P., Zhang, X.-P., Coventry, P. F., and Zhang, R. (2016). Start-Up Control of an Offshore Integrated Mmc Multi-Terminal Hvdc System with Reduced Dc 
Voltage. IEEE Trans. Power Syst. 31 (4), 2740-2751. doi:10.1109/ tpwrs.2015.2466600

Wang, Y., Yuan, Z., and Fu, J. (2016). A Novel Strategy on Smooth Connection of an Offline Mmc Station into Mtdc Systems. IEEE Trans. Power Deliv. 31 (2), 568-574. doi:10.1109/tpwrd.2015.2437393

Wang, G., Liu, R., Zhao, N., Ding, D., and Xu, D. (2019). Enhanced Linear Adrc Strategy for Hf Pulse Voltage Signal Injection-Based Sensorless Ipmsm Drives. IEEE Trans. Power Electron. 34 (1), 514-525. doi:10.1109/ tpel.2018.2814056

Xiang, W., Lin, W., An, T., Wen, J., and Wu, Y. (2017). Equivalent Electromagnetic Transient Simulation Model and Fast Recovery Control of Overhead Vsc-Hvdc Based on Sb-Mmc. IEEE Trans. Power Deliv. 32 (2), 778-788. doi:10.1109/ tpwrd.2016.2607230

Yang, H., Dong, Y., Li, W., and He, X. (2017). Average-Value Model of Modular Multilevel Converters Considering Capacitor Voltage Ripple. IEEE Trans. Power Deliv. 32 (2), 723-732. doi:10.1109/ tpwrd.2016.2555983

Yang, H., Li, W., Lin, L., and He, X. (2018). Decoupled Current Control with Synchronous Frequency Damping for $\mathrm{Mmc}$ Considering Sub-Module Capacitor Voltage Ripple. IEEE Trans. Power Deliv. 33 (1), 419-428. doi:10.1109/tpwrd.2017.2721961

Zhang, L., Zou, Y., Zou, Y., Yu, J., Qin, J., Vijay, V., et al. (2017). Modeling, Control, and protection of Modular Multilevel Converter-Based Multi-Terminal HVDC
Systems: A Review. CSEE J. Power Energ. Syst. 3 (4), 340-352. doi:10.17775/ cseejpes.2017.00440

Conflict of Interest: HY was employed by the company Heyuan Power Supply Bureau of Guangdong Power Grid Co. Ltd.

The remaining authors declare that the research was conducted in the absence of any commercial or financial relationships that could be construed as a potential conflict of interest.

Publisher's Note: All claims expressed in this article are solely those of the authors and do not necessarily represent those of their affiliated organizations, or those of the publisher, the editors and the reviewers. Any product that may be evaluated in this article, or claim that may be made by its manufacturer, is not guaranteed or endorsed by the publisher.

Copyright (C) 2021 Xianyong, Zijuan, Yaohong, Li, Weikuan and Jian. This is an open-access article distributed under the terms of the Creative Commons Attribution License (CC BY). The use, distribution or reproduction in other forums is permitted, provided the original author(s) and the copyright owner(s) are credited and that the original publication in this journal is cited, in accordance with accepted academic practice. No use, distribution or reproduction is permitted which does not comply with these terms. 